\title{
The Analysis of the Cold Flat Rolling Process by Salf Program
}

\author{
Gilberto Thiago de Paula Costa ${ }^{a}$, Carlos Augusto dos Santos ${ }^{b *}$
${ }^{a}$ Radioactive Waste Management Department, Brazilian Nuclear Energy Commission, Rua General Severiano 90, Botafogo, CEP: 22290-040, Rio de Janeiro, RJ, Brazil
${ }^{b}$ Department of Mechanical Engineering, School of Engineering, Fluminense Federal University, Rua Passos da Pátria 156, São Domingos, CEP:24210-240, Niterói, RJ, Brazil

Received: October 25, 2016; Revised: February 06, 2017; Accepted: February 18, 2017

\begin{abstract}
SALF program is a Brazilian program developed to simulate the cold flat rolling process by the finite element method. The program uses the implicit and rigid-plastic approaches to perform numerical analyses. This article presents the cold flat rolling simulations performed by SALF, where the variables of rolling force, effective strain rate, and effective strain were analyzed. The simulations were chosen from the literature and involved materials such as steel and aluminum, with thicknesses of $1.0 \mathrm{~mm}$ and $3.0 \mathrm{~mm}$, reductions of $5 \%, 16.67 \%$, and $30 \%$, and friction coefficients of $0.08,0.1$, and 0.3 . The results showed that SALF describes the above variables appropriately in qualitative and quantitative terms. However, based on the research results, domestic steel industries may now use a national program to simulate the cold flat rolling process to improve their processes and products.
\end{abstract}

Keywords: Cold Flat Rolling Process; Finite Element Method; Implicit and Rigid-Plastic Approaches

\section{Introduction}

The cold flat rolling process provides raw material for several industries such as electronics, appliances, and transportation. Examples of raw materials include sheets used in personal computers, appliances, cars, planes, and locomotives. It is also important to reinforce that the volume of rolled steel in Brazil reached 17.0 million tons in first three quarters of 2015, 8.2 million tons being flat-rolled products $^{1}$. Cold flat-rolled products in the same period reached 2.0 million tons, $24.4 \%$ of flat-rolled products, and $11.8 \%$ of Q1-Q3 production ${ }^{1}$. According to the above facts, cold flat-rolled products play a vital role in the economy.

Analyses of the cold flat rolling process have been performed using one or more of following approaches: analytical, numerical, and experimental. In general, analytical studies involve applications of uniform energy, slab, or upper-bound methods ${ }^{2-6}$. These methods present limitations involving geometries of processes and descriptions of material hardening. Because of these limitations, the methods are commonly used as starting points to estimate the forming load in simple processes: upsetting, flat rolling, drawing, and extrusion. The finite element method (FEM) has been used in the majority of numerical analyses. The FEM advantage consists in describing a large number of process variables in a short time period: distribution of effective strain and stress, load and torque rolling, raw material defects, friction hill, and damage $\mathrm{e}^{7-13}$. The experimental approach serves to provide real data and is fundamental to understand the process. Tests

\footnotetext{
* e-mail: solracbr@gmail.com
}

performed either on the actual equipment, on the idealized prototypes, or in the labs furnish the experimental data ${ }^{14-17}$. In relation to analytical and numerical analyses, this approach demands more time and costs with equipment, raw material, and manual labor.

The analytical methods have remained unchanged since the Mid-20th Century. However, FEM has developed constantly, and its application enhances understanding of the flat rolling process. Improvements in measurement equipment have been the most significant developments in the experimental area. Based on these three considerations, traditional analytical methods continue to be used only to estimate the forming load in simple processes. FEM plays an important role because it provides an overall understanding of the process variables in a short time period. The experimental approach remains important inside analyses because its experimental data validate the FEM results.

The first commercial FEM program, DEFORM 2D and 3D (USA), dedicated to simulate metal forming processes, appeared in 1990, following the development of automated mesh generation and workstation processing capability ${ }^{18}$. Over time, other commercial programs have been developed, such as: FORGE (France) ${ }^{19}$, QFORM (Russia) ${ }^{20}$, MSCForge $\left(\text { USA }^{21}, \text { ABAQUS (USA) }{ }^{22} \text {, and SIMUFACT (Germany) }\right)^{23}$. The full version of these programs enables users to perform 2D or 3D simulations involving analyses of the following phenomena: mechanics (stress, strain or damage distribution), heat transfer, phase transformation, and diffusion ${ }^{18}$. A basic FEM program devoted to metal forming processes only performs mechanical analyses, specifically stress and strain evaluations. 
This program works as a seed to develop more elaborate programs involving heat transfer, phase transformation, or diffusion analyses because they depend on the mechanical evaluations of stress and strain.

In Brazil, the steel industries producing cold flat-rolled products still lack a national FEM program to simulate the flat rolling process. These companies use international FEM programs, such as those mentioned above. Licensing is expensive, and technical support is frequently unable to solve simulation problems. However, developing research in Brazil to create a national FEM software program is crucial. Such software will enable domestic steel industries to incorporate recent technology to improve their products and processes.

This article introduces SALF program, Sistema de Análise de Laminação a Frio, a cold flat rolling analysis system. The program is the first Brazilian tool directed at simulating the cold flat rolling process using FEM. SALF performs simulations focused on mechanical phenomena, specifically stress and strain analyses. The second section of the article shows the mathematical theory employed to develop the software. However, this part of the article contributes to disseminate the information necessary to create FEM programs of this nature. The information will help developers design software like SALF or develop more elaborate programs that analyze other phenomena such as heat transfer, phase transformation, and diffusion, thereby increasing the number of national software programs dedicated to metal forming processes. SALF development involved ideas of structured and object-oriented programming using FORTRAN 90 language. Preprocessing and post processing were developed using the oriented-object approach, while the processor used the structured approach.

\section{Theoretical Approach}

The program was developed based on the implicit and flow formulations ${ }^{7}$, specifically adapted for the cold flat rolling process. The following items present the key points of this development.

\subsection{Basic definitions}

This part of the process involves describing the initial data to start the simulation: sheet and roll geometrical characteristics; mechanical behavior of material; friction and velocity boundary conditions; and governing equations. The universal curve defines mechanical behavior. This curve relates the effective stress to the effective strain rate. The friction model characterizes the shear stress in the surface between sheet and roll. The chosen model for this program was the constant frictional stress. The sheet and roll velocities represent the velocity conditions. The governing equations of the simulation are related in (1), respectively: equilibrium equations, yield criteria, constitutive equations, and compatibility conditions.

$$
\begin{aligned}
& \frac{\partial \sigma_{\mathrm{ij}}}{\partial \mathrm{x}_{\mathrm{j}}}=0 \\
& \left(\sigma_{\mathrm{x}}-\sigma_{\mathrm{y}}\right)^{2}+\left(\sigma_{\mathrm{y}}-\sigma_{\mathrm{z}}\right)^{2}+\left(\sigma_{\mathrm{z}}-\sigma_{\mathrm{x}}\right)^{2}+ \\
& 6\left(\tau_{\mathrm{xy}}^{2}+\tau_{\mathrm{yz}}^{2}+\tau_{\mathrm{zx}}^{2}\right)=2 \mathrm{Y}^{2} \\
& \dot{\varepsilon}_{\mathrm{ij}}=\frac{3}{2} \frac{\dot{\bar{\varepsilon}}}{\sigma} \sigma_{\mathrm{ij}}^{\prime} \\
& \dot{\varepsilon}_{\mathrm{ij}}=\frac{1}{2}\left(\frac{\partial \mathrm{u}_{\mathrm{i}}}{\partial \mathrm{x}_{\mathrm{j}}}+\frac{\partial \mathrm{u}_{\mathrm{j}}}{\partial \mathrm{x}_{\mathrm{i}}}\right)
\end{aligned}
$$

In (1), $\sigma$ represents the stress tensor components, $\mathrm{x}$ characterizes the global coordinate, $\mathrm{Y}$ is the yield strength, $\dot{\varepsilon}$ corresponds to the strain rate tensor components, $\dot{\bar{\varepsilon}}$ is the effective strain rate, $\bar{\sigma}$ characterizes the effective stress, $\sigma^{\prime}$ is the deviatoric stress tensor components, and $\mathrm{u}$ represents the nodal velocity.

\subsection{Domain discretization}

Discretization consists in dividing the interest domain (sheet or sheet/roll) in several elements to create a mesh, with shared element-sides. The node velocity in the shared element-side is the same for both elements. Figure 1 shows a mesh created for a rolling simulation.

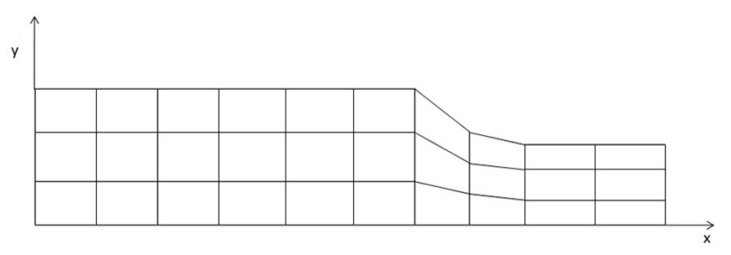

Figure 1. Example of mesh in flat rolling.

The mesh uses four-noded and four-sided isoparametric elements, with the velocities in any element part described by

$$
\left\{\begin{array}{l}
\mathrm{u}_{\mathrm{x}}(\xi, \eta)=\sum \mathrm{q}_{\alpha}(\xi, \eta) \cdot \mathrm{u}_{\mathrm{x}}^{\alpha} \\
\mathrm{u}_{\mathrm{y}}(\xi, \eta)=\sum \mathrm{q}_{\alpha}(\xi, \eta) \cdot \mathrm{u}_{\mathrm{x}}^{\alpha}
\end{array}\right\}
$$

where $\alpha$ represents the nodal point, $q_{\alpha}$ its shape function, and $u_{x}^{\alpha}$ and $u_{y}^{\alpha}$ are the nodal velocities in the global coordinates. The shape function value in any part of the element is calculated from

$$
\mathrm{q}_{\alpha}(\xi, \eta)=\frac{1}{4}\left(1+\xi_{\alpha} \xi\right)\left(1+\eta_{\alpha} \eta\right)
$$

with the variables $\xi$ and $\eta$ representing the local coordinate system for the element.

\subsection{Establishing the element equation}

The variational described in (4) defines the element equation, where the first term characterizes the work performed 
by internal forces, and the second, the work performed by external forces. The variables $\bar{\sigma}$ and $\dot{\bar{\varepsilon}}$ are respectively, the effective stress and effective strain rate, both being functions of the velocity field variable. The term $\mathrm{F}_{\mathrm{i}}$ is the prescribed stress on the sheet boundary, and $u_{i}$ represents the velocity. Equation (4) requires that the solution field satisfies the compatibility, incompressibility, and boundary conditions, in addition to providing a stationary value to the variational.

$$
\pi=\int_{\mathrm{v}} \bar{\sigma} \dot{\bar{\varepsilon}} \mathrm{dv}-\int_{\mathrm{s}} \mathrm{F}_{\mathrm{i}} \mathrm{u}_{\mathrm{i}} \mathrm{ds}
$$

The required stationary value comes from the equation defined in (5). The second term in this equation represents the penalized form of the incompressbility ${ }^{11}$ used to remove the incompressibility constraint in the velocity field.

$$
\begin{aligned}
& \delta \pi=\int_{\mathrm{v}} \bar{\sigma} . \delta \dot{\bar{\varepsilon}} \mathrm{dv}+\mathrm{K} \int_{\mathrm{v}} \dot{\varepsilon}_{\mathrm{v}} \delta \dot{\varepsilon}_{\mathrm{v}} \mathrm{dv}- \\
& \int_{\mathrm{s}} \mathrm{F}_{\mathrm{i}} \delta \mathrm{u}_{\mathrm{i}} \mathrm{ds}=0
\end{aligned}
$$

In (5), $\mathrm{K}$ corresponds to the penalty constant. The effective strain rate $\dot{\bar{\varepsilon}}$ and volumetric strain rate $\dot{\varepsilon_{\mathrm{v}}}$ depend on the strain rate tensor

$$
\dot{\varepsilon}_{\mathrm{ij}}=\frac{1}{2} \sum_{\alpha}\left(\frac{\partial q_{\alpha}}{\partial \mathrm{x}_{\mathrm{j}}} \mathrm{u}_{\mathrm{i}}^{\alpha}+\frac{\partial \mathrm{q}_{\alpha}}{\partial \mathrm{x}_{\mathrm{i}}} \mathrm{u}_{\mathrm{j}}^{\alpha}\right)
$$

which assumes the matrix format

$$
\begin{aligned}
& \dot{\varepsilon}=\text { B.u }
\end{aligned}
$$

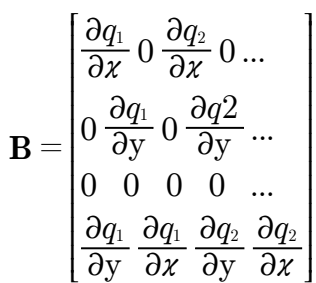

with $B$ representing the strain rate matrix of the element and $u$ representing the nodal velocity vector of the element. The components in matrix B correspond to the partial derivatives of the shape function in relation to the global coordinates. The third line in B presents zero entrances because in the width direction of cold flat rolling processes, the plain strain condition prevails. Adopting the strain rate tensor, the effective strain rate and volumetric strain rate are defined as

$$
\begin{gathered}
\dot{\bar{\varepsilon}}=\left(\mathrm{u}^{\mathrm{T}} \mathrm{B}^{\mathrm{T}} \mathrm{DBu}\right)^{\frac{1}{2}}=\left(\mathrm{u}^{\mathrm{T}} \mathrm{Pu}\right)^{\frac{1}{2}} \\
\mathrm{P}=\mathrm{B}^{\mathrm{T}} \mathrm{DB} \quad(10) \\
\mathrm{D}=\left[\begin{array}{llll}
\frac{2}{3} & 0 & 0 & 0 \\
0 & \frac{2}{3} & 0 & 0 \\
0 & 0 & \frac{2}{3} & 0 \\
0 & 0 & 0 & \frac{1}{3}
\end{array}\right]
\end{gathered}
$$

$$
\begin{gathered}
\dot{\varepsilon}_{\mathrm{v}}=\mathrm{C}^{\mathrm{T}} \mathrm{u}=\mathrm{C}_{\mathrm{i}} \mathrm{u}_{\mathrm{i}} \\
\mathrm{C}_{\mathrm{i}}=\mathrm{B}_{\mathrm{li}}+\mathrm{B}_{2 \mathrm{i}}+\mathrm{B}_{3 \mathrm{i}}
\end{gathered}
$$

The solution in (5) consists in solving the non-linear equation system defined in (14), where $u_{i}$ represents the nodal velocities in the $\mathrm{x}$ and $\mathrm{y}$ directions. A set of eight equations is established for each element because of the two degrees of freedom in each node.

$$
\frac{\delta \pi}{\delta u_{i}}=0
$$

The system in (14) requires an iterative method for its solution due to its nonlinearity. The Newton-Raphson method has been the most used in metal forming simulations. The first step of the method characterizes a linearization of (14) by Taylor expansion, which results in the following equation

$$
\frac{\delta \pi}{\delta u_{i}}+\left[\frac{\partial^{2} \pi}{\partial u_{i} \partial u_{j}}\right] \Delta u_{j}=0
$$

The term $\Delta \mathrm{u}_{\mathrm{j}}$ in (15) represents the first-order correction of the velocities, and the others characterize integrals with the following discretized form

$$
\begin{aligned}
& \frac{\delta \pi}{\delta u_{\mathrm{i}}}=\int_{\mathrm{v}} \frac{\bar{\sigma}}{\overline{\bar{\varepsilon}}} P_{\mathrm{ij}} u_{\mathrm{j}} d v+K \\
& \int_{\mathrm{v}} C_{\mathrm{j}} \mathrm{u}_{\mathrm{j}} C_{\mathrm{i}} d v-\int_{\mathrm{s}} F_{\mathrm{j}} N_{\mathrm{ji}} d s \\
& \frac{\delta^{2} \pi}{\delta u_{\mathrm{j}} \delta u_{\mathrm{j}}}=\int_{\mathrm{v}} \frac{\bar{\sigma}}{\overline{\bar{\varepsilon}}} P_{\mathrm{ij}} d v+K \\
& \int_{\mathrm{v}} C_{\mathrm{j}} C_{\mathrm{i}} d v+\int_{\mathrm{v}}\left(\frac{1}{\overline{\bar{\varepsilon}}} \frac{\delta \bar{\sigma}}{\delta \bar{\varepsilon}}-\frac{\bar{\sigma}}{\overline{\bar{\varepsilon}}^{2}}\right) \frac{1}{\overline{\bar{\varepsilon}}} P_{\mathrm{ik}} u_{\mathrm{k}} u_{\mathrm{m}} P_{\mathrm{mj}} d v
\end{aligned}
$$

with $\mathrm{P}$ and $\mathrm{D}$ defined in (10) and (11), and $\mathrm{N}$ described in terms of the shape functions in (17).

$$
\mathbf{N}=\left[\begin{array}{cc}
q_{1} & 0 \\
0 & q_{1} \\
q_{2} & 0 \\
0 & q_{2} \\
\ldots & \ldots
\end{array}\right]
$$

\subsection{Definition and solution of the global equation}

The definition procedure of the global equation involves transferring each elemental equation obtained in the previous item to the global one, using an appropriate index system. This equation presents a similar form as (15), however the number of entrances at force and velocity correction vectors differs. In the global form, these vectors have twice the mesh degrees of freedom in terms of entrances. The stiffness global matrix is square, its order being the same as the vectors mentioned. When the procedure is finished, a linear equation as (18) appears, related to each degree of 
freedom with the equation variables corresponding to the nodal velocities. In (18), the k parameter defines all elements sharing the velocity $u_{i}$.

$$
\sum_{\mathrm{k}}\left(\frac{\partial \pi_{\mathrm{j}}}{\partial \mathrm{u}_{\mathrm{i}}}+\frac{\partial^{2} \pi_{\mathrm{j}}}{\partial \mathrm{u}_{\mathrm{i}} \partial \mathrm{u}_{\mathrm{j}}} \Delta \mathrm{u}_{\mathrm{j}}\right)=0
$$

The Gaussian Elimination method has been used to solve the linear equation system obtained from (18). The method employs the norm defined in (19) to verify the convergence of the Newton-Raphson method

$$
\begin{gathered}
\text { error } \leq \frac{\|\boldsymbol{\Delta} \mathbf{u}\|}{\|\mathbf{u}\|} \\
\|\mathbf{u}\|=\left(\mathbf{u}^{\mathrm{T}} \mathbf{u}\right)^{1 / 2}
\end{gathered}
$$

with $\Delta \mathbf{u}$ characterizing the correction velocity vector and $\mathbf{u}$, the vector velocity. In general, this norm should be smaller than $5 \times 10^{-5}$.

\subsection{Geometry updating, stress tensor, and total effective strain}

The nodal velocities are updated using the vector $\Delta \mathrm{u}$ obtained from the convergence of the Newton-Raphson method. The new velocity field enables redefining the nodal coordinates using the equations described in (20)

$$
\begin{aligned}
& \mathrm{x}=\mathrm{x}_{0}+\mathrm{u}_{\mathrm{x}} \Delta t \\
& \mathrm{x}=\mathrm{y}_{0}+\mathrm{u}_{\mathrm{y}} \Delta t
\end{aligned}
$$

where $\mathrm{x}_{0}$ and $\mathrm{y}_{0}$ represent the previous nodal coordinates, and $\Delta t$ the step time size.

Defining the stress tensor employs the ideas described in 2.1, and the equation in (21) defines how to obtain the total effective strain

$$
\bar{\varepsilon}_{t+\Delta t}=\bar{\varepsilon}_{t}+\dot{\bar{\varepsilon}} \Delta t
$$

with $\bar{\varepsilon}_{t}$ representing the total effective strain of previous step and $\dot{\bar{\varepsilon}}$ the effective strain rate in the current step.

\subsection{Rolling force}

The stress tensor of the nodal points in contact with the roll furnishes information to obtain the rolling pressure along the arc of contact. Rotation of this tensor according to the specific angle produces the normal stress component acting on the roll for each nodal point along the arc of contact. Using these stress components, the integral in (22) furnishes the roll force per unit of width

$$
\frac{\mathrm{F}}{\mathrm{w}}=\int \mathrm{p} . \mathrm{ds}=\sum_{\mathrm{n}} \mathrm{w}_{\mathrm{n}} \mathrm{p}\left(\mathrm{x}_{\mathrm{n}}\right)
$$

with $\mathrm{w}_{\mathrm{n}}$ representing the weight factor, $\mathrm{x}_{\mathrm{n}}$ characterizing the integration point, and $\mathrm{p}\left(\mathrm{x}_{\mathrm{n}}\right)$ representing the normal stress in the integration point.

\section{Evaluation of the Program}

The first evaluation step consisted of comparing force results recorded in the simulations from the literature and those obtained from SALF when repeating the simulations with the program. The chosen simulations were based on conditions representing the raw materials and thicknesses that are commonly involved in cold flat rolling, as shown in Table 1. In simulations 4 and 5, a study of the effective strain and effective strain rate was also performed. The data with an asterisk in the table were chosen from other articles due to the lack of their definitions in the reference article.

The control data for simulations in Table 1, time per step, limiting strain rate, and penalty constant were 0.001 $\mathrm{s}, 0.01 \mathrm{~s}^{-1}$, and 10,000.00, respectively. In simulations 5 and 6 , the article of reference provided the element number used in the mesh. In the other simulations, the element number followed a proportion in relation to simulations 5 and 6 .

\section{Results}

\subsection{Force results}

In simulations 1 and 2 in Table 1 , the article of reference used the procedure described in RAMBERG and OSGOOD 25 to define the flow stress curve of the material employed in the simulations. The procedure used the Young's modulus of the material and the stresses obtained in the strain values of

\begin{tabular}{|c|c|c|c|c|c|c|c|c|}
\hline Simulation & Material & $\begin{array}{c}\text { Initial } \\
\text { thickness } \\
(\mathrm{mm})\end{array}$ & Reduction & $\begin{array}{l}\text { Sheet length } \\
(\mathrm{mm})\end{array}$ & $\begin{array}{c}\text { Roll } \\
\text { diameter } \\
(\mathrm{mm})\end{array}$ & $\begin{array}{c}\text { Roll angular } \\
\text { velocity } \\
(\mathrm{rad} / \mathrm{s})\end{array}$ & $\begin{array}{c}\text { Sheet } \\
\text { velocity } \\
(\mathrm{mm} / \mathrm{s})\end{array}$ & $\begin{array}{l}\text { Coefficient } \\
\text { of friction }\end{array}$ \\
\hline 1 & Steel 1 & 1 & $5 \%$ & $10^{*}$ & 130 & 3.86 & $220 *$ & 0.08 \\
\hline 2 & Steel 1 & 1 & $30 \%$ & $10^{*}$ & 130 & 3.86 & $220 *$ & 0.08 \\
\hline 3 & Steel 2 & 1 & $5 \%$ & $10 *$ & 130 & 3.86 & $220 *$ & 0.08 \\
\hline 4 & Steel 2 & 1 & $30 \%$ & $10^{*}$ & 130 & 3.86 & $220 *$ & 0.08 \\
\hline 5 & Aluminium & 3 & $16.67 \%$ & 20 & 100 & 6.28 & 104.72 & 0.1 \\
\hline 6 & Aluminium & 3 & $16.67 \%$ & 20 & 100 & 6.28 & 104.72 & 0.3 \\
\hline
\end{tabular}
$0.1 \%$ and $0.2 \%$ to describe the whole curve. Figure 2 shows the curve obtained according to the above ideas.

Considering the conditions of simulations 1 and 2, Table 2 presents the force results from the analytical methods, SALF, FEM from ESCRIBANO, et al. ${ }^{24}$, and the experimental data.

Table 1. Simulations chosen from the literature $\mathrm{e}^{11,24}$. 


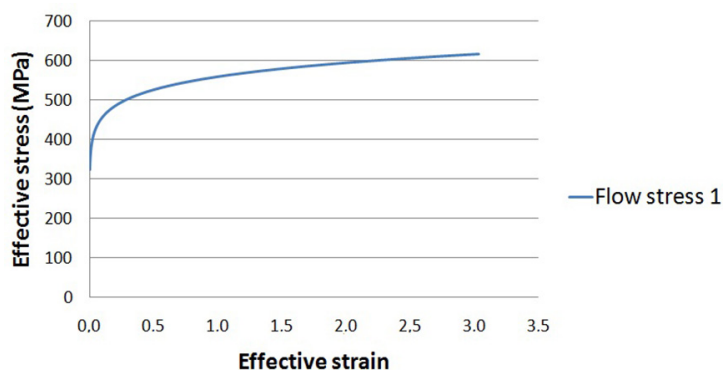

Figure 2. Flow stress curve used in simulations 1 and 2.

Neither SALF nor FEM from ESCRIBANO, et al. ${ }^{24}$ presented a relevant approximation between their results and the experimental data. The analytical homogeneous deformation method underestimated the experimental data while the slab method presented data close to the experimental data. All the results in Table 2 present the anticipated force behavior in relation to the reduction: the force results increased as a higher reduction was employed.

It is noteworthy that despite using the flow stress curve obtained following to the procedure in RAMBERG and OSGOOD $^{25}$, SALF simulation presented force values below those in FEM from ESCRIBANO, et al. ${ }^{24}$ shown in Table 2. Because of the procedural uncertainties, a set of new simulations using SALF were performed. These simulations employed a flow stress curve with a higher work hardening coefficient in relation to the curve in Figure 2. Figure 3 shows the flow stress curve that produced the best force results, as explained above.

Table 3 presents the force results as in Table 2, with SALF simulations using the flow stress curve of Figure 3. According to the data in Table 3, SALF presented excellent force results in relation to the experimental force values. However, these new simulations in Table 3 showed that in qualitative and quantitative terms, SALF is able to correctly describe the relation between force versus reduction.

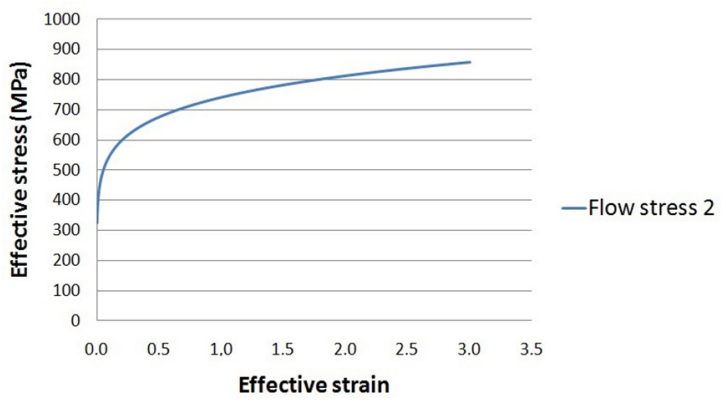

Figure 3. Flow stress curve used in simulations 3 and 4.

The relation between force versus friction was analyzed in simulations 5 and 6 in Table 1. The material for these simulations was aluminum with a Young's modulus of 69.0 GPA, as described in the reference article. However, considering the size of this Young's modulus, a flow stress obtained from the literature ${ }^{26}$ was employed in SALF simulations, shown in Figure 4. The roll and sheet velocities were provided in the reference article.

Table 4 shows strong agreement between the force results of SALF and CAWTHORN et al. ${ }^{11}$. In these simulated conditions, the analytical results overestimated the numerical force results of SALF and CAWTHORN et $a l .{ }^{11}$. A constancy of the force results with the variation of the friction coefficient was observed in SALF and CAWTHORN et al. ${ }^{11}$. This constancy was also presented in PRAKASH, et al. ${ }^{8}$. However, the results in this analysis demonstrated the SALF potential in describing the relation between force and friction.

\subsection{Effective strain rate and effective strain results}

Figures 5 and 6 illustrate the effective strain rate results related to simulations 4 and 5, respectively. According to these figures, the effective strain rate variable has a high

Table 2. Force versus reduction - simulation 1: reduction of 5\%; simulation 2: reduction of $30 \%$.

\begin{tabular}{ccccccc}
\hline Simulation & Material & $\begin{array}{c}\text { Homogeneous } \\
\text { deformation } \\
\text { method }\end{array}$ & Slab method & SALF & $\begin{array}{c}\text { FEM } \\
\text { ESCRIBANO, } \\
\text { et al. }^{24}\end{array}$ & $\begin{array}{c}\text { Experimental } \\
\text { ESCRIBANO, } \\
\text { et al. }^{24}\end{array}$ \\
\hline $1(\mathrm{~N} / \mathrm{mm})$ & $\begin{array}{c}\text { Steel - flow stress by } \\
\text { RAMBERG } \\
\text { and }\end{array}$ & 769 & 1228 & 747 & 1400 & 1100 \\
$2(\mathrm{~N} / \mathrm{mm})$ & OSGOOD $^{25}$ & 2095 & 3307 & 2012 & 3400 & 3150 \\
\hline
\end{tabular}

Table 3. Force versus reduction - simulation 3: reduction of 5\%; simulation 4: reduction of $30 \%$.

\begin{tabular}{lcccccc}
\hline Simulation & Material & $\begin{array}{c}\text { Homogeneous } \\
\text { deformation } \\
\text { method }\end{array}$ & Slab method & SALF & $\begin{array}{c}\text { FEM } \\
\text { ESCRIBANO, } \\
\text { et al. }{ }^{24}\end{array}$ & $\begin{array}{c}\text { Experimental } \\
\text { ESCRIBANO, } \\
\text { et al. }{ }^{24}\end{array}$ \\
\hline $3(\mathrm{~N} / \mathrm{mm})$ & $\begin{array}{c}\text { Curve with } \\
\text { modified } \\
\text { hardening } \\
\text { coefficient }\end{array}$ & 2464 & 1451 & 1073 & 1400 & 1100 \\
\hline$(\mathrm{N} / \mathrm{mm})$ & & 4223 & 3140 & 3400 & 3150 \\
\hline
\end{tabular}




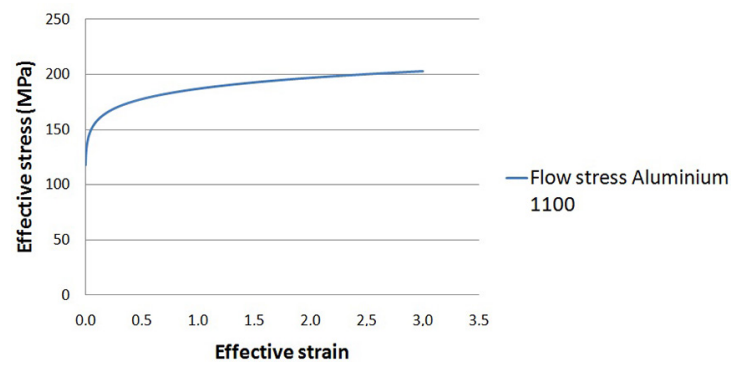

Figure 4. Flow stress curve used in simulations 5 and 6.

value at the beginning of the contact between the steel and roll. As the material is processed, the value decreases along the interface of the sheet and roll. In the literature ${ }^{6}$, the region presenting a small value of the effective strain rate, below the interface of the sheet and roll, is called restricted flow zone. Inside this zone, the material presents a small deformation, causing an excessive pressure on the central material. The excessive pressure produces the high value of the effective strain rate at the central region in figures 5 and 6. Near the end of the sheet and roll contact region, the restricted flow zone disappears and the effective strain rate presents a small increase. The rate distribution in simulations 4 and 5 is similar to that observed by LIN and SHEN $^{27}$ and $\mathrm{KOMORI}^{28}$.

Effective Strain Rate

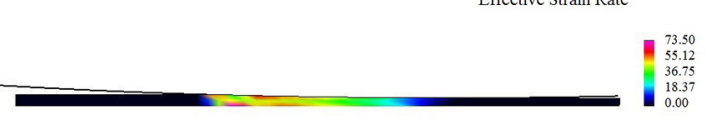

Figure 5. Effective strain rate - thickness of $1.0 \mathrm{~mm}$, velocity of $250.00 \mathrm{~mm} / \mathrm{s}$ and reduction of $30 \%$ (simulation 4 ).

Effective Strain Rate

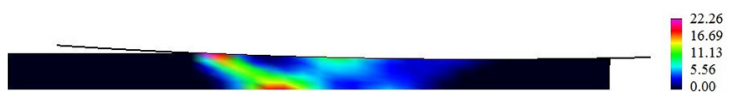

Figure 6. Effective strain rate - thickness of $3.0 \mathrm{~mm}$, velocity of $104.72 \mathrm{~mm} / \mathrm{s}$ and reduction of $16.67 \%$ (simulation 5 ).

In relation to the effective strain, results in Figures 7 and 8 show an increasing strain value from the beginning of the reduction to the exit of the sheet. The higher values of effective strain after the sheet leaves the roll appear on the sheet surface and in its central region. This behavior is a consequence of the effective strain rate results: the higher values of this variable also appear on the sheet surface and in its central region. The results shown in Figures 7 and 8 are similar to those from RICHELSEN ${ }^{29}$.
Effective Strain

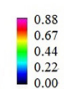

Figure 7. Effective strain - thickness of $1.0 \mathrm{~mm}$, velocity of 250.00 $\mathrm{mm} / \mathrm{s}$ and reduction of $30 \%$ (simulation 4 ).

Effective Strain

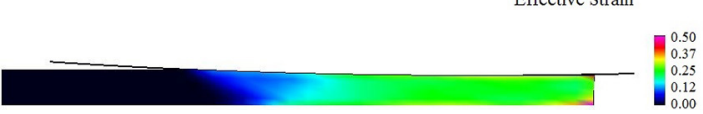

Figure 8. Effective strain rate - thickness of $3.0 \mathrm{~mm}$, velocity of $104.72 \mathrm{~mm} / \mathrm{s}$ and reduction of $16.67 \%$ (simulation 5).

\section{Conclusions}

According to the results in the above item, the SALF program permits simulating the cold flat rolling process. However, domestic steel industries now have a national tool to simulate their processes using FEM. In future SALF tests, simulating other rolling conditions using data obtained from steel industries will be vital. These new simulations will provide information about the program performance inside the whole range of conditions in the cold flat rolling process, revealing any necessary program adjustments.

The content presented in the article disseminates the knowledge necessary to develop FEM programs focused on simulating metal forming processes. However, based on this article, other national developers can create more metal forming programs, thereby increasing the number of related national software products.

Additionally, SALF is the seed program for future research simulating the flat rolling process by analyzing damage, heat transfer, and phase transformation. Including these analyses will allow SALF to be efficiently used throughout the entire universe of the flat rolling process.

\section{References}

1. SICETEL. Sindicato Nacional das Indústrias de Trefilação e Laminação de Metais Ferrosos. Estatísticas Setoriais. Available from: <http://www.sicetel.org.br/>. Acess in: Feb 29/02/2016.

2. Thomsen EG, Charles TY, Kobayashi S. Plastic Deformation in Metal Processing. $1^{\text {st }}$ ed. London: Macmillan; 1965. 486 p.

3. Avitzur B, Choi JC, Kim BM. Upper-bound solutions for several metal-forming processes. In: $14^{\text {th }}$ NAMRC: North American Manufacturing Research Conference Proceedings; 1986 May 28-30; University of Minnesota, Minneapolis, MN, USA. p. 406-413.

4. Hosford WF, Caddell RM. Metal Forming - Mechanics and Metallurgy. $2^{\text {nd }}$ ed. New Jersey: Prentice Hall PTR; 1993.

Table 4. Force versus friction - simulation 5: coefficient of friction of 0.1 ; simulation 6: coefficient of friction of 0.3 .

\begin{tabular}{lccccc}
\hline Simulation & Material & $\begin{array}{c}\text { Homogeneous } \\
\text { deformation method }\end{array}$ & Slab method & SALF & $\begin{array}{c}\text { FEM CAWTHORN } \\
\text { et al. }{ }^{11}\end{array}$ \\
\hline $5(\mathrm{kN})$ & Aluminium & 24.40 & 31.61 & 19.78 & 20.00 \\
$6(\mathrm{kN})$ & Aluminium & 24.40 & 40.02 & 19.57 & 22.00 \\
\hline
\end{tabular}


5. Bresciani F, Zavaglia CAC, Button ST, Gomes E, Nery FAC. Conformação Plástica dos Metais. $5^{\mathrm{a}}$ ed. Campinas: Unicamp, 1997.

6. Helman H, Cetlin PR. Fundamentos da Conformação Mecânica dos Metais. $2^{\mathrm{a}}$ ed. Belo Horizonte: Artliber; 2005.

7. Kobayashi OS, Oh SI, Altan T. Metal Forming and Finite Element Method. $1^{\text {st }}$ ed. New York: Oxford University Press; 1989.

8. Prakash RS, Dixit PM, Lal GK. Steady-state plane-strain cold rolling of a strain-hardening material. Journal of Materials Processing Technology. 1995;52(2-4):338-358.

9. Abo-Elkhier M. Elasto-plastic finite element modelling of strip cold rolling using Eulerian fixed mesh technique. Finite Elements in Analysis and Design. 1997;27(4):323-334.

10. Jiang ZY, Wei D, Tieu AK. Analysis of cold rolling of ultra thin strip. Journal of Materials Processing Technology. 2009;209(9):4584-4589.

11. Cawthorn CJ, Loukaides EG, Allwood JM. Comparison of analytical models for sheet rolling. Procedia Engineering. 2014;81:2451-2456.

12. Chen J, Chandrashekhara K, Mahimkar C, Lekakh SN, Richards VL. Void closure prediction in cold rolling using finite element analysis and neural network. Journal of Materials Processing Technology. 2011;211(2):245-255.

13. Mashayekhi M, Torabian N, Poursina M. Continuum damage mechanics analysis of strip tearing in a tandem cold rolling process. Simulation Modelling Practice and Theory. 2011;19(2):612-625.

14. Cetlin PR, Mesquita ELA. Plasticina na análise de deformação na laminação. Metalurgia ABM. 1979;35:829-832.

15. Thomson PF, Brown JH. A study of deformation during cold rolling using visioplasticity. International Journal of Mechanical Sciences. 1982;24(9):559-576.

16. Cetlin PR, Lisboa RSM, Garcia F. Otimização da laminação de desbaste através da simulação física utilizando plasticina. In: Anais do XXXII Seminário de Laminação de Processos e Produtos Laminados e Revestidos; 1995; Curitiba, PR, Brasil. São Paulo: Édile Serviços Gráficos e Editora; 1995. p. 597-608.

17. Fonseca TC, Lisboa RSM, Pinheiro IP, Cetlin PR. Emprego da plasticina na determinação do coeficiente de atrito na conformação mecânica. In: Anais do XXXIV Seminário de Laminação - Processos e Produtos Revestidos e Laminados. 1997; Belo Horizonte, MG, Brasil. São Paulo: Édile Serviços Gráficos e Editora. 1997. p. 331-340.

18. Furrer D, Semiatin SL. ASM Handbook, Volume 22A: Fundamentals of Modeling for Metals Processing. Materials Park: ASM International; 2009.

19. Scientific Forming Technologies Corporation. DEFORM. Available from: $<$ http://www.deform.com/>. Acess in: 28/01/2017.

20. QFORM Metal Forming Simulation Software. Available from: $<$ http://www.qform3d.com/>. Acess in: 28/01/2017.

21. MSC Software. Available from: <http://www.mscsoftware. com/>. Acessed in: 28/01/2017.

22. Dassalt Systems. ABAQUS. Available from: $<$ https://www.3ds. com/products-services/simulia/products/abaqus/>. Acess in: $28 / 01 / 2017$

23. MSC Software. SIMUFACT. Available from: $<$ http://www. mscsoftware.com/product/simufact $>$. Acess in: 28/01/2017.

24. Escribano R, Lostado R, Martínez-de-Pisón FJ, Pernía A, Vergara E. Modelling a Skin-Pass Rolling Process by Means of Data Mining Techniques and Finite Element Method. International Journal of Iron and Steel Research. 2012;19(5):43-49.

25. Ramberg W, Osgood WR. Description of Stress-Strain Curves by Three Parameters. Washington: National Advisory Committee for Aeronautics; 1943.

26. ASM International. Atlas of Stress-Strain Curves. $2^{\text {nd }}$ ed. Materials Park: ASM International; 2002

27. Lin ZC, Shen CC. A rolling process two-dimensional finite element model analysis. Finite Elements in Analysis and Design. 1997;26(2):143-160.

28. Komori K. Rigid-plastic finite element method for analysis of three-dimensional rolling that requires small memory capacity. International Journal of Mechanical Sciences. 1998;40(5):479-491.

29. Richelsen AB. Elastic-plastic analysis of the stress and strain distribution in asymmetric rolling. International Journal of Mechanical Sciences. 1997;39(11):1199-1211. 